\title{
Development of Asset Fault Signatures for Prognostic and Health Management in the Nuclear Industry
}

\section{IEEE International Conference on Prognostics and Health Management}

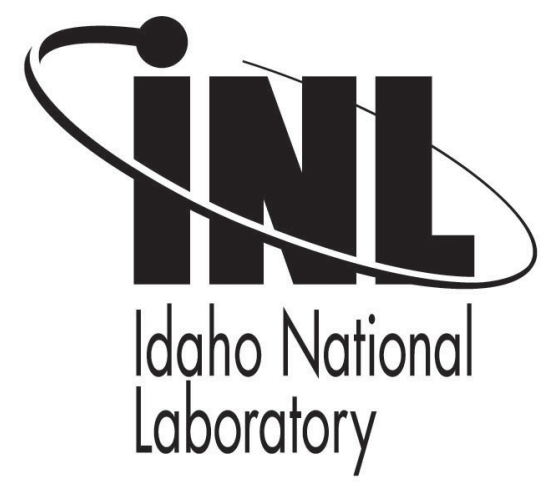

\section{June 2014}




\section{Development of Asset Fault Signatures for Prognostic and Health Management in the Nuclear Industry}

\author{
Vivek Agarwal and Nancy J. Lybeck \\ Department of Human Factors, Controls, \\ and Statistics \\ Idaho National Laboratory \\ Idaho Falls, ID 83415, USA \\ \{vivek.agarwal, nancy.lybeck\}@inl.gov
}

\author{
Randall Bickford \\ Expert Microsystems \\ Orangevale, CA 95662, USA \\ rbickford@expmicrosys.com
}

\author{
Richard Rusaw \\ Nuclear Division \\ Electric Power Research Institute \\ Charlotte, NC 28262, USA \\ rrusaw@epri.com
}

\begin{abstract}
Proactive online monitoring in the nuclear industry is being explored using the Electric Power Research Institute's Fleet-Wide Prognostic and Health Management (FW-PHM) Suite software. The FW-PHM Suite is a set of web-based diagnostic and prognostic tools and databases that serves as an integrated health monitoring architecture. The FW-PHM Suite has four main modules: (1) Diagnostic Advisor, (2) Asset Fault Signature Database, (3) Remaining Useful Life Advisor, and (4) Remaining Useful Life Database. This paper focuses on development of asset fault signatures to assess the health status of generator step-up generators and emergency diesel generators in nuclear power plants. Asset fault signatures describe distinctive features based on technical examinations that can be used to detect a specific fault type. At the most basic level, fault signatures are comprised of an asset type, a fault type, and a set of one or more fault features (symptoms) that are indicative of the specified fault. The Asset Fault Signature Database is populated with asset fault signatures via a content development exercise that is based on the results of intensive technical research and on the knowledge and experience of technical experts. The developed fault signatures capture this knowledge and implement it in a standardized approach, thereby streamlining the diagnostic and prognostic process. This will support the automation of proactive online monitoring techniques in nuclear power plants to diagnose incipient faults, perform proactive maintenance, and estimate the remaining useful life of assets.
\end{abstract}

Keywords- asset fault signatures; generator step-up transformers; emergency diesel generators; fleet-wide monitoring

\section{INTRODUCTION}

As the operating life of nuclear power plant (NPP) systems is extended beyond the original licensing period, the need arises for more sophisticated ways to monitor component performance. One approach toward addressing this challenge is the growing trend of moving from periodic, manual assessments and surveillances of physical components and structures to online condition monitoring. This is an important transformational step in the management of NPPs, enabling real-time assessment and monitoring of physical systems and better management of components based on their performance. Of particular importance will be the capability to determine the remaining useful life (RUL) of a component to justify its continued operation over an extended plant life.
The U.S. Department of Energy, Office of Nuclear Energy funds the Light Water Reactor Sustainability Program to develop the scientific basis to extend the operation of commercial light water reactors beyond the current 60 -year licensing period. The Advanced Instrumentation, Information, and Control Systems Pathway under the Light Water Reactor Sustainability Program is collaborating with the Electric Power Research Institute's (EPRI's) Long-Term Operations Program to conduct research and development on technologies that can be used to enhance the long-term reliability, productivity, and safety of aging light water reactors. One of the primary areas of focus for the Light Water Reactor Sustainability and LongTerm Operations Programs is online monitoring of active assets in the nuclear industry.

An important objective of the research for online monitoring of active assets is to implement predictive online monitoring for the existing fleet of NPPs. EPRI's Fleet-Wide Prognostic and Health Management (FW-PHM) Suite software was selected for use as a demonstration platform. The FWPHM Suite was specifically developed by EPRI for use in the commercial power industry (both nuclear and fossil fuel). EPRI and Idaho National Laboratory (INL) are working with nuclear utility partners to develop asset fault signatures in the FWPHM Suite software for generator step-up transformers (GSUs) and emergency diesel generators (EDGs). The nuclear utility partners include Shearon Harris Nuclear Generating Station (owned by Duke Progress Energy) for GSUs and Braidwood Generating Station (owned by Exelon Nuclear) for EDGs.

This paper presents a detailed description of fault signature development and the attributes of fault signatures. Examples of fault signatures are presented that show different fault signature attributes and their structure in the Asset Fault Signature (AFS) Database. The paper is organized as follows. Section II briefly describes the FW-PHM Suite software architecture. Different attributes associated with a fault signature and steps involved in developing a fault signature are described in Section III. A representative is presented in Section IV for both EDG and GSU. Finally, conclusions and future research are presented in Section V. 


\section{FleEt-Wide PROGNOSTIC AND HEALTH MANAGEMENT SUITE}

The FW-PHM Suite software is an integrated suite of web-based diagnostic and prognostic tools and databases, developed for EPRI by Expert Microsystems and is specifically designed for use in the commercial power industry (for both nuclear and fossil fuel generating plants). The FW-PHM Suite serves as an integrated health management framework (as shown in Figure 1), managing the functionality needed for complete implementation of diagnostics and prognostics [1]. The FW-PHM Suite consists of four main modules: (1) the Diagnostic Advisor, (2) the Asset Fault Signature Database, (3) the Remaining Useful Life Advisor, and (4) the Remaining Useful Life Database. The FW-PHM Suite has the capability to perform diagnosis and prognosis at different hierarchical levels, from the component level to the plant level, across a fleet of power units.

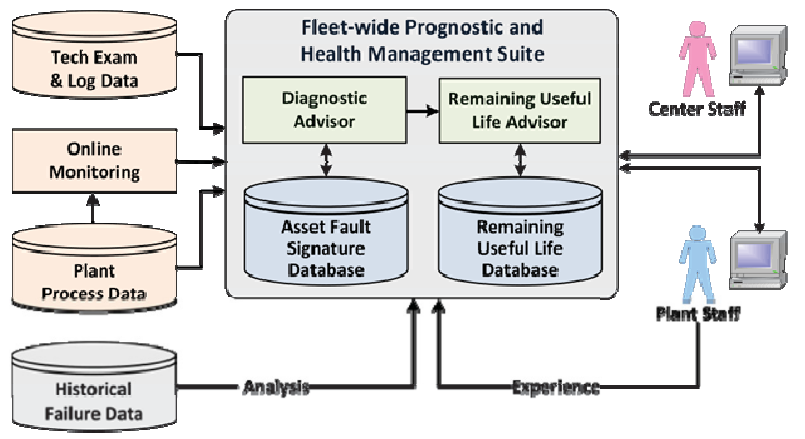

Figure 1. Data flow in the EPRI FW-PHM Suite [1].

The FW-PHM Suite uses AFSs as a structured representation of the information that an expert would use to first detect and then verify the occurrence of a specific type of fault [1]. A fault describes a particular mode of degradation that can be detected through analysis of plant information before the asset condition reaches the point of failure to meet a service requirement. An assumption is implied that the fault is detectable through analysis of plant information and that the analysis can be performed in time to prevent or otherwise remedy the fault condition before it becomes a failure.

Fault signatures are developed for application to a specific type of asset; therefore, they are organized with reference to that type of asset. However, it is desirable to specify fault signatures as broadly as possible to be used in the entire industry. The fault signatures defined in this paper can be applied to comparable assets used in similar service environments.

The four primary modules in the FW-PHM Suite are described in more detail as follows:

\section{A. Asset Fault Signature Database}

The ASF Database organizes fault signatures collected from the many EPRI member utilities. At the most basic level, fault signatures are comprised of an asset type, a fault type, and a set of one or more fault features (symptoms) that are indicative of the specified fault. Each installation of the software has two separate database schemas: (1) the master database maintained and distributed by EPRI and (2) a local database containing data developed at the NPPs or fleet monitoring center. Locally developed information can be exported and sent to EPRI for evaluation and possible inclusion in the master database that is shared amongst EPRI members. The process of developing fault signatures to populate the AFS Database is described in $[2,3]$, as well as discussed in detail in Section III of this paper.

\section{B. Diagnostic Advisor}

The Diagnostic Advisor identifies possible faults by comparing ASFs with operating data. The Diagnostic Advisor is expected to be used on a daily (or other periodic) basis by technicians who are monitoring the health of a specific asset in the plant. Using either online data sources or information that is input manually (or a combination of online and offline data), the Diagnostic Advisor presents the most likely faults (if any) based on the available information and, when appropriate, recommends additional information that might be used to discriminate amongst the possible faults. The Diagnostic Advisor is expected to streamline the diagnosis process by helping the technician focus his/her efforts on the most likely faults and possible causes, based on the operating behavior of the system.

\section{Remaining Useful Life Advisor}

The RUL Advisor calculates RUL for an asset, based on the model type, model parameters, input process parameters, and diagnostic information from the Diagnostic Advisor. The RUL Advisor is expected to be used on a periodic basis by technicians who are monitoring the health of a specific asset in the plant.

\section{Remaining Useful Life Database}

The RUL Database organizes asset RUL signatures (i.e., models) collected from across the industry. At the most basic level, an RUL signature is comprised of an asset type, a model type, and model calibration parameters. An RUL Signature also defines limiting conditions that defines the endof-life. The model type definition includes specification of the input variables needed to run the model. Subject matter experts from the power industry, EPRI, and EPRI's partners/subcontractors will most likely develop RUL signatures.

Each implementation of FW-PHM consists of the EPRI master database and a local user-developed database. Users can incorporate new attributes for an existing fault signature or add new fault signatures as the need arises. For example, additional fault features identified as part of offline data mining could be implemented. Users may choose to periodically export their databases for review (shown in Figure 2). EPRI will evaluate new information for inclusion in the master database and periodically publish updates to the master database.

INL is working with subject matter experts from industry, EPRI, and EPRI's partners/subcontractors to develop fault signatures for GSUs and EDGs. The developed fault signatures are a structured representation of essential information used by experts to detect the occurrence of a specific type of fault. Although early detection of emergent faults is highly desirable, this must be balanced with the likelihood of a false alarm. 


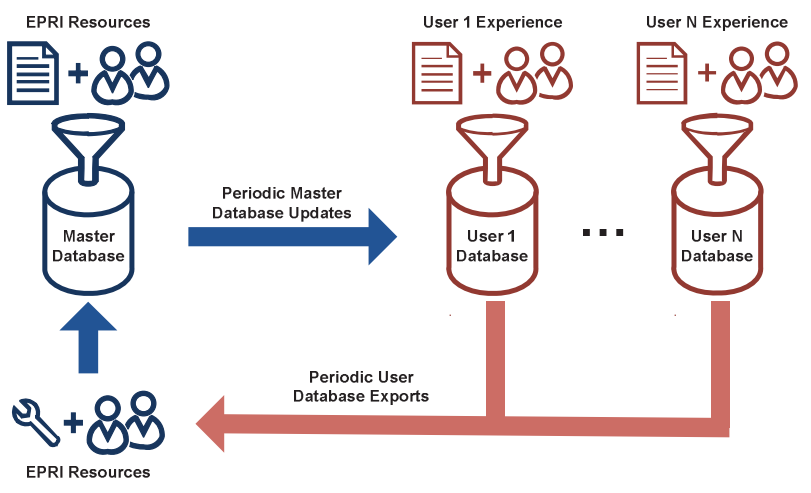

Figure 2. EPRI master database and user local database aggregation and periodic master database updates [1].

\section{ASSET FAULt Signatures}

\section{A. Attributes of a Fault Signature}

A fault signature is always associated with an asset type and a fault type. Asset types represent a specific definition of an asset, with consideration given to the nature of its use in service within a particular kind of NPP or NPP application. Bushings within a GSU transformer are an example of an asset type (shown in Figure 3). Asset subtypes represent a generalized definition of asset, without consideration given to the nature of its use in service within a particular kind of NPP or NPP application. Each asset type is associated with an asset subtype, attributes, and their values that are used to further discriminate between subtypes (shown in Figure 4) (e.g., the attribute bushing type is associated with the values draw-lead and fixed-conductor).

\section{Asset Type Hierarchy}

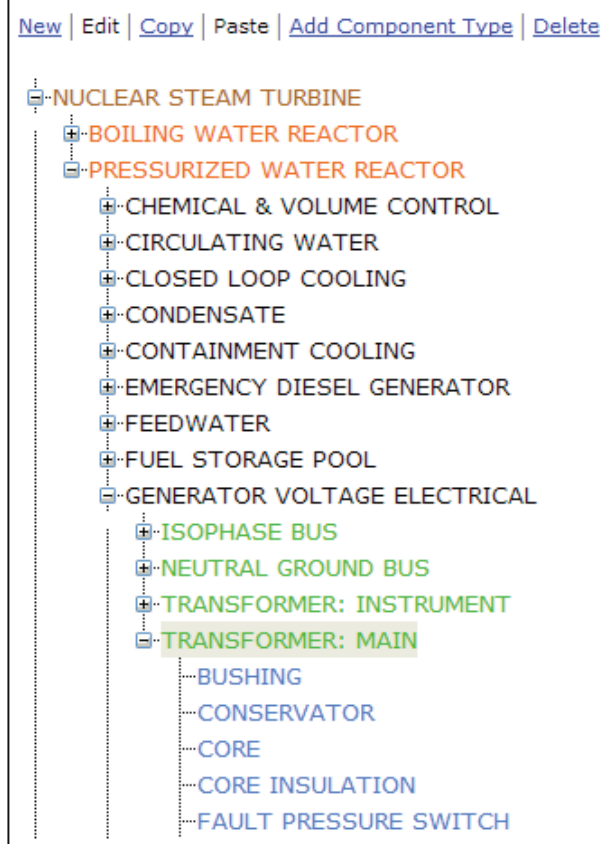

Figure 3. An example of asset types.

Fault types represent a specific definition of a fault, with consideration given to its location and to the nature of its use within a particular kind of NPP or NPP application. Paper insulation degradation in a transformer winding is an example of a fault type (shown in Figure 5). Fault attributes and their values provide a way to discriminate specific fault causes (e.g., arcing and cellulose degradation are two of the fault attributes of paper insulation degradation).

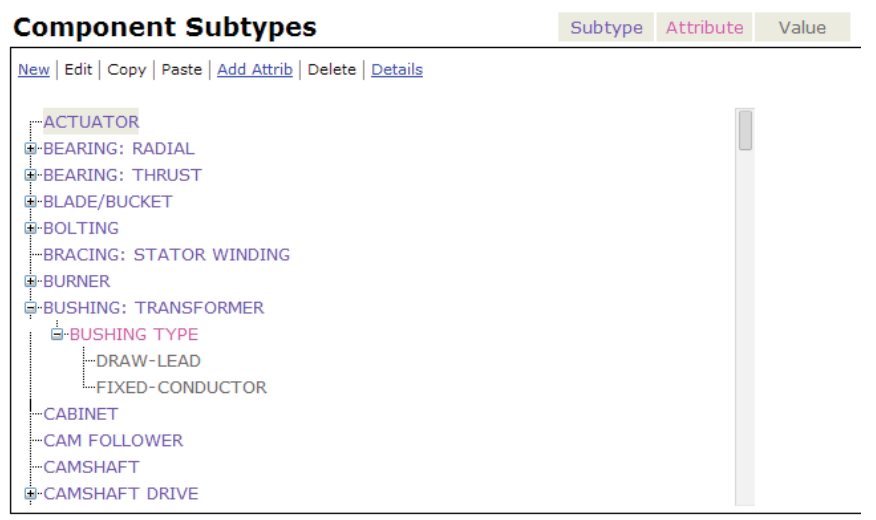

Figure 4. An example of asset subtypes at the component level.

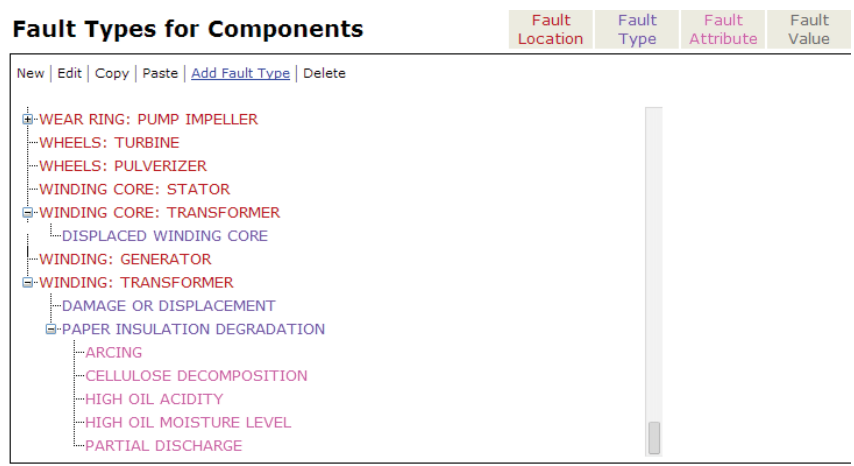

Figure 5. An example of fault types at the component level for transformer winding.

A fault type has a fault signature list, where characteristics known as fault features are defined and can be used to detect and verify the fault. Fault features represent the unique state of one or more parameters indicating a faulty condition. In addition, fault description, causes, effects, and remedies are defined in fault signatures.

Asset type, fault type, and asset subtypes are organized into five discrete levels within the AFS database: (1) plant, (2) unit, (3) system, (4) equipment, and (5) component. A structured and organized representation of a fault signature in the AFS Database allows easy manipulation and management of fault signature by computers.

\section{B. Developing Fault Signatures}

A step-by-step procedure for developing an ASF includes the following four steps (shown in Figure 6):

1. Specify the asset type for which the fault signature(s) is to be developed. For the specified asset type, gather information on its operating range, mechanisms of degradation, and observable features that can detect the degrading conditions. The information can be gathered from multiple sources such as EPRI's Preventive Maintenance Basis Database, Fossil Maintenance 


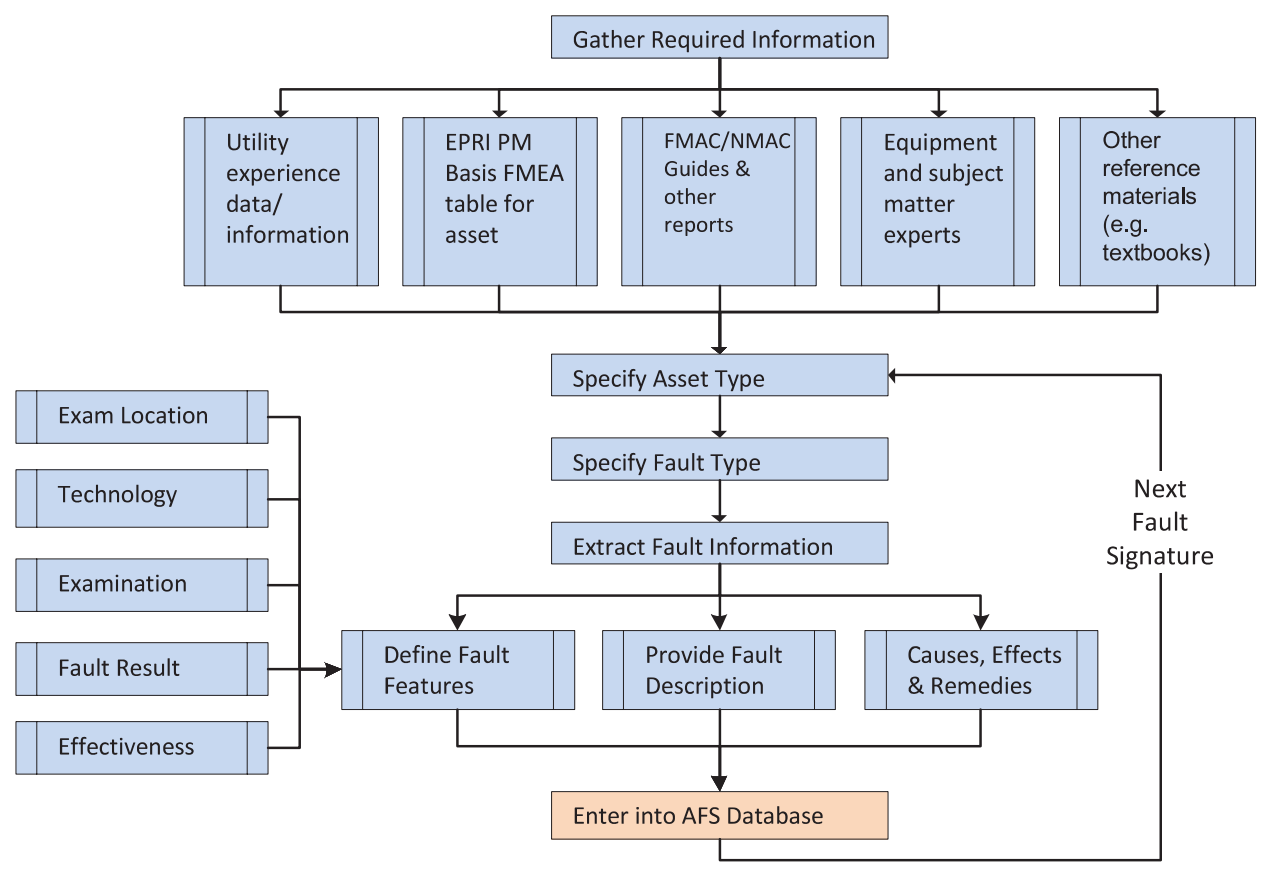

Figure 6. Steps involved in gathering ASFs [6].

Application Center and Nuclear Maintenance Application Center, and from other notable sources (e.g., textbooks, equipment guide, and publications).

2. Specify the fault type and any narrowing attributes that can be used to make the fault more specific. For example, the most common fault type associated with transformer winding is paper insulation degradation. Fault attributes such as arcing, cellulose decomposition, high oil acidity, high oil moisture level, and partial discharge are commonly used to identify the root cause of paper insulation degradation in a transformer winding.

3. For each fault type, fault signatures are developed. For each fault signature, specify a fault feature comprised of information on (1) location that the plant data are collected; (2) technology or technologies used to identify the fault (e.g., oil analysis in transformers); (3) examination (e.g., particle content, gas analysis, or moisture content) and outcome of examination (i.e., the result, whether normal, abnormal, high, low, marginal, or unacceptable); and (4) the effectiveness (e.g., low, medium, high, or very high) of the fault feature in detecting the fault condition. A fault type can have more than one fault signature with more than one fault feature.

4. Provide a description of the fault condition, possible causes, remedies, and effects on the asset (if left uncorrected).

Note that some fault features might be common to more than one fault signature. For example, in the case of GSUs, the acid number of the transformer insulating oil is a common fault feature for two fault signatures: high acidity and paper insulation degradation due to electrical discharge (see Figure 7). In this situation, the effectiveness of the fault feature serves as a differentiating factor and is used by the Diagnostic Advisor to rank the possible diagnoses.

Several fault signatures have been developed and implemented in the AFS Database as part of a knowledge transfer exercise with utility partners for GSUs [2, 4] and EDGs $[2,5]$. The developed fault signatures were implemented into the AFS Database, based on the procedure described in [6]. The ability of the FW-PHM Suite's Diagnostic Advisor to diagnose primary winding paper insulation degradation in a GSU and improper valve timing in an EDG based on the implemented fault signatures into the AFS Database is presented in $[2,3]$.

\section{EXAMPLE FAULT SignATURES}

\section{A. Generator Step-Up Transformer Fault Signatures}

Primary winding paper insulation degradation is one of the common faults in transformers [7]. The two most common modes of primary winding paper insulation degradation in GSUs are electrical (due to electrical discharge) and thermal (due to thermal degradation).

Paper insulation degradation due to electrical discharge represents the occurrence of either a partial discharge phenomenon or an arcing phenomenon. Figure 7 shows that the significant fault features associated with this degradation involve monitoring gas concentration levels of acetylene and hydrogen, both individually and jointly. The acidity of the insulating oil is also a fault feature.

The technology commonly used to measure individual gas concentrations in the transformer insulating oil is dissolved gas analysis. A steep increase in the hydrogen concentration compared to other dissolved gases in the transformer insulating oil is an indication of partial discharge. Similarly, 
an increase in both hydrogen and acetylene concentrations compared to other dissolved gases is an indication of arcing. A steep increase in the hydrogen concentration level is the primary indication of paper insulation degradation due to electrical discharge; therefore, its effectiveness is very high when compared to the hydrogen and acetylene concentrations.

An increase in the acidity level of the insulating oil will lead to insulation degradation, which, in turn, would accelerate the possibility of electrical discharge because the dielectric strength of the paper insulation decreases.

Figure 8 shows that the significant fault features associated with thermal paper insulation degradation involve monitoring the concentration of carbon monoxide (the key indicator) and the concentration of carbon dioxide from dissolved gas analysis. For each measured concentration of carbon monoxide and carbon dioxide, the ratio of carbon monoxide to carbon dioxide is computed. An increase in temperature inside the transformer due to localized heating or due to loss of cooling systems for an extended period causes the cellulose material of the primary winding paper insulation to degrade and generate carbon monoxide (primarily) and carbon dioxide gases. A steep increase in the carbon monoxide concentration level and corresponding decrease in the carbon dioxide to carbon monoxide ratio indicates thermal degradation of primary winding paper insulation. The carbon monoxide fault feature is assigned a very high effectiveness for thermal degradation of the primary winding insulation.

It is important to prevent the primary winding from operating at excess temperature (i.e., above the operating limit) for a prolonged period of time because it could deteriorate the credibility of the winding insulation. Therefore, the primary winding temperature is also a viable fault feature.

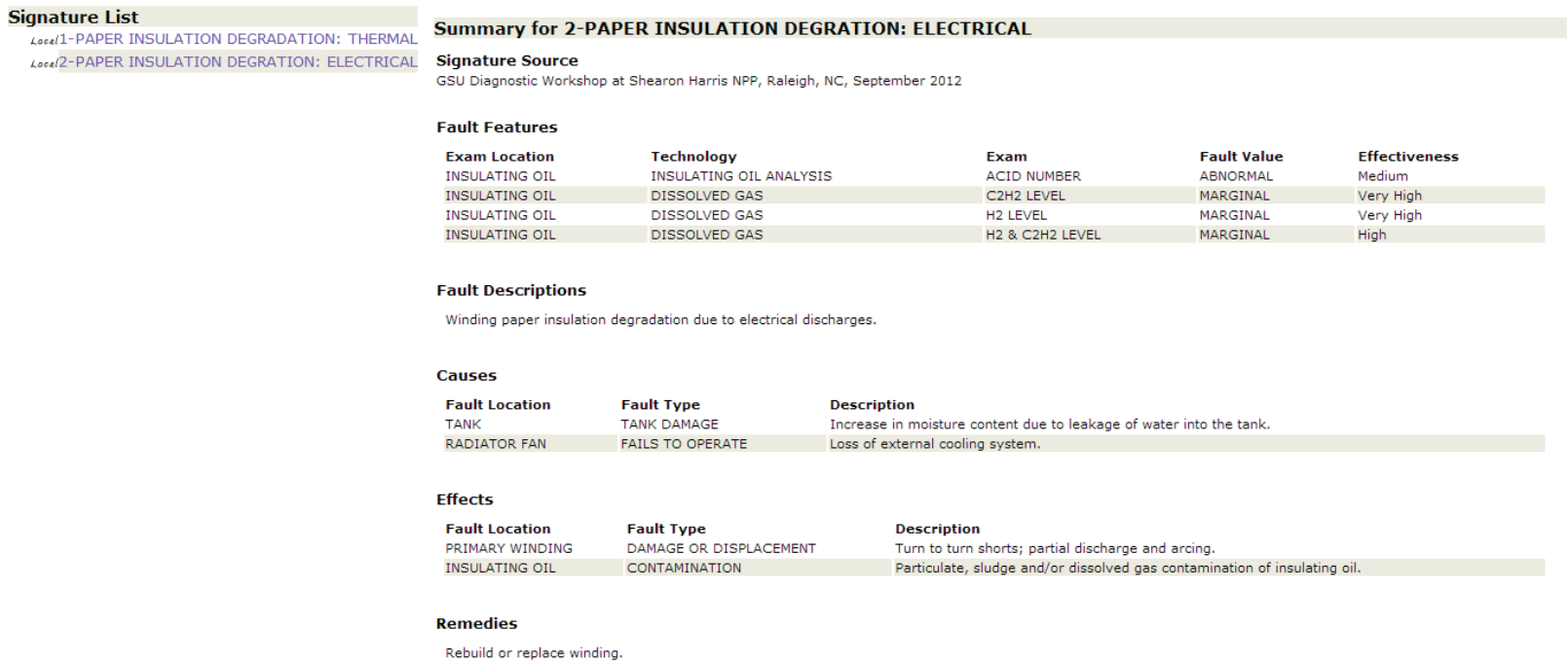

Figure 7. Paper insulation degradation: electrical fault signature and associated fault features.

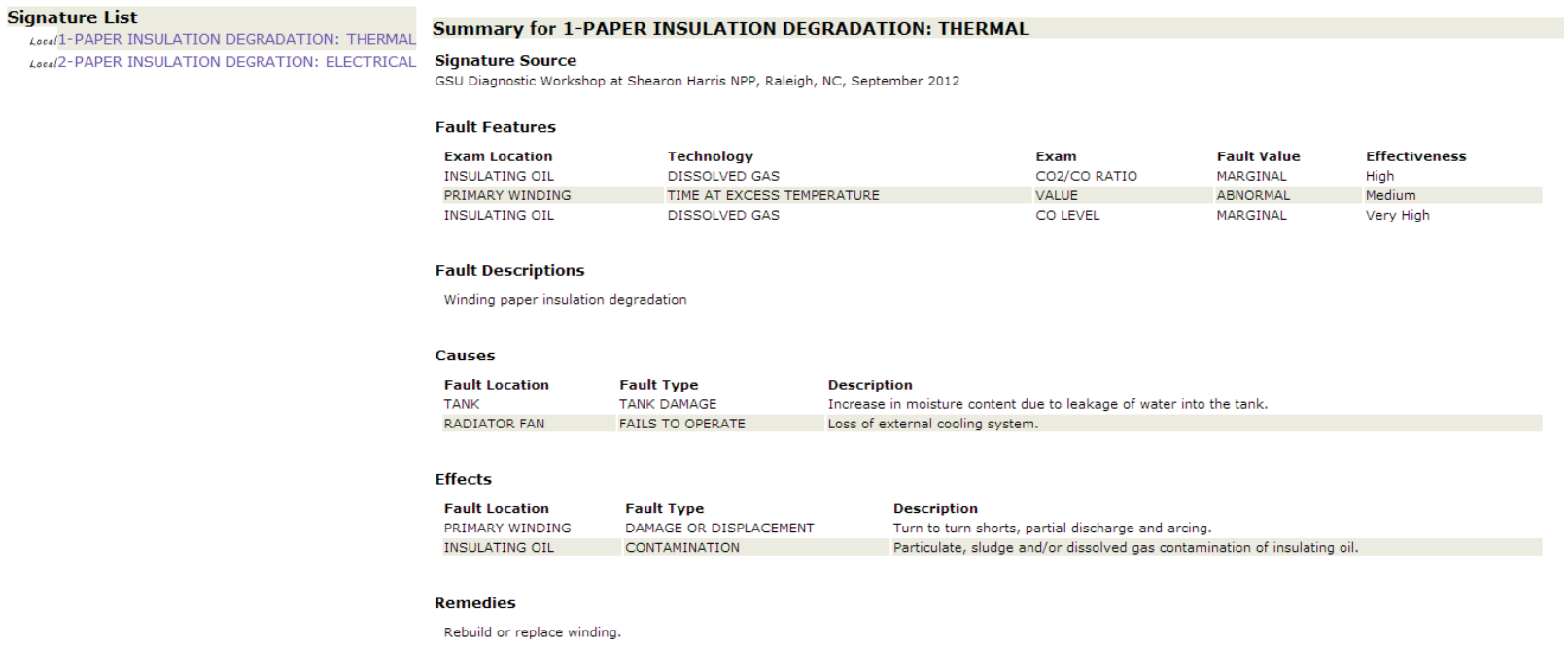

Figure 8. Paper insulation degradation: thermal fault signature and associated fault features. 


\section{B. Emergency Diesel Generator Fault Signature}

EDGs are safety-related assets that are required to operate reliably if the external grid power supply to an NPP is interrupted. EDGs are required to start, run, and take the basic load that is essential for safe shutdown of the NPP. There are many faults that could lead to EDG failure. One of the faults is improper valve timing (alternately referred to as ignition timing) for the diesel engine cylinder. Figure 9 shows the improper valve timing fault signature implemented in the AFS Database. Exhaust temperature analyses (i.e., the temperature measured at each diesel cylinder and the temperature differential between diesel cylinders) are identified as significant fault features that could be used to diagnose improper valve timing in diesel engines.

Figures 6-8 list the possible causes, effects, and remedies associated with each fault type. This information could be used to assist plant maintenance engineers in optimizing maintenance activities.
Several faults signatures for GSUs and EDGs have been implemented in the AFS Database; verification and validation of these fault signatures are pending. A demonstration showing the ability of the FW-PHM Suite to diagnose a developing fault is documented in a report [3] and in a video [8]. Emerging faults were simulated by adding drifts to plant data. The demonstration highlights the ability of the software to identify faults based on evolving symptoms, using both online and offline data sources.

\section{CONCLUSIONS AND FUTURE WORKS}

This paper presented different attributes of an AFS that allows a structured representation of the information captured from different sources. Development of a representative GSU fault signature and EDG fault signature was discussed. Implementation fault signatures in the AFS Database of the FW-PHM Suite for GSUs and EDGs will serve as a foundation for implementation of automated online monitoring for GSUs and EDGs in the nuclear industry.

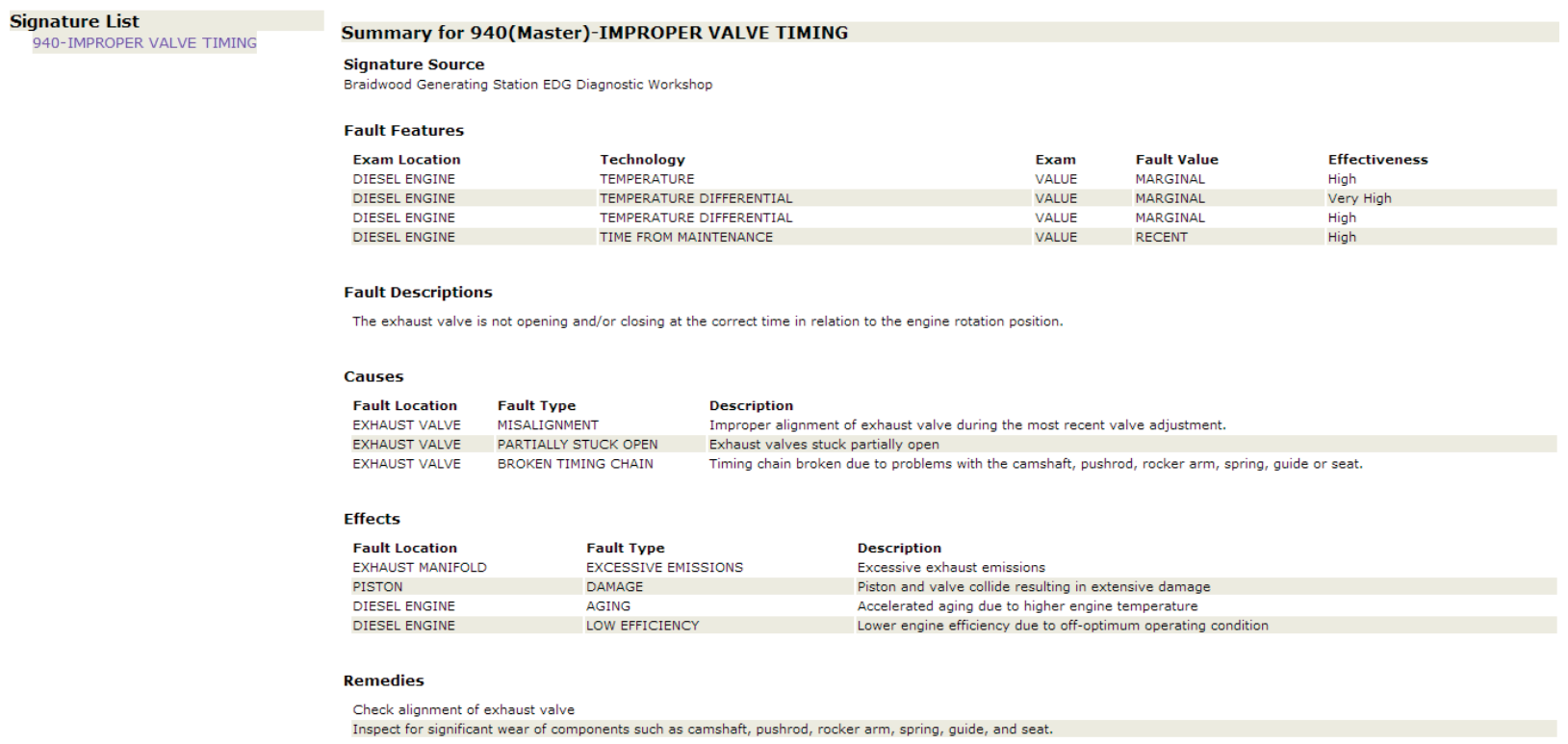

Figure 9. Diesel engine improper valve timing fault signature and associated fault features.

In the future, EPRI and INL will continue to work with nuclear utility partners to develop and verify a full set of fault signatures covering a wide range of recognized faults for GSUs and EDGs, enabling implementation in NPPs.

\section{ACKNOWLEDGMENT}

The authors would like to thank Kirk Fitzgerald (INL) and Rahul Palnitkar (Expert Microsystems) for their substantial support. The research work was supported by the Light Water Reactor Sustainability Program at INL, funded by the U.S. Department of Energy under U.S. Department of Energy Idaho Operations Office Contract DE-AC07-05ID14517.

\section{DISCLAIMER}

This information was prepared as an account of the work sponsored by an agency of the U.S. Government. Neither the U.S. Government nor any agency thereof, nor any of their employees, makes any warranty, expressed or implied, or assumes any legal liability or responsibility for the accuracy, completeness, or usefulness, of any information, apparatus, product, or process disclosed, or represents that its use would not infringe privately owned rights. References herein to any specific commercial product, process, or service by trade name, trade mark, manufacturer, or otherwise, does not necessarily constitute or imply its endorsement, recommendation, or favoring by the U.S. Government or any agency thereof. The views and opinions of authors expressed herein do not necessarily state or reflect those of the U.S. Government or any agency thereof.

\section{REFERENCES}

[1] Electric Power Research Institute (EPRI). Fleet-Wide Prognostics and Health Management Application Research. Report EPRI 1026712. Electric Power Research Institute, Charlotte, NC, 2012. 
[2] V. Agarwal, N. J. Lybeck, B. T. Pham, R. Rusaw, and R. Bickford, "Online monitoring of plant assets in the nuclear industry," Annual Conference of the Prognostics and Health Management Society, October, New Orleans, USA, 2013.

[3] V. Agarwal, N. J. Lybeck, L. C. Matacia, and B. T. Pham, "Demonstration of online monitoring for generator step-up transformers and emergency diesel generators," Technical Report INL/EXT-1330155. Idaho National Laboratory, Idaho Falls, ID, 2013.

[4] N. J. Lybeck, V. Agarwal, B. T. Pham, H. Medema, and K. Fitzgerald, "Online monitoring technical basis and analysis framework for large power transformers," Interim Report INL/EXT-12-27181. Idaho National Laboratory, Idaho Falls, ID, 2012.

[5] B. T. Pham, N. J. Lybeck, and V. Agarwal, "Online monitoring technical basis and analysis framework for emergency diesel generators," Interim Report INL/EXT-12-27754. Idaho National Laboratory, Idaho Falls, ID, 2012.

[6] Electrical Power Research Institute (EPRI). Asset fault signature requirements. software manual. Electric Power Research Institute, Charlotte, NC, 2012.

[7] W. H. Bartley. "Analysis of Transformer Failures," Proceedings of the 36th Annual Conference on International Association of Engineering Insurers, 2003.

[8] Online Monitoring for Improved Power Plant Equipment Operating Life and Productivity, EPRI, 2012.

http://www.youtube.com/watch?v=8JCchydWlcg\&feature $=\mathrm{c} 4-$ overview\&list $=$ UUctcciH1NrAGpwMnKwvnLgQ 